Check for updates

Cite this: New J. Chem., 2021, 45, 4506

DOI: 10.1039/d1nj90018h

rsc.li/njc

\section{Correction: An anionic and cationic surfactant- assisted hydrothermal synthesis of cobalt oxide nanoparticles as the active electrode material for supercapacitors}

\author{
R. R. Samal, ${ }^{\text {ab }}$ Aneeya K. Samantara, ${ }^{\text {cd }}$ S. Mahalik, ${ }^{\text {ab }}$ J. N. Behera, ${ }^{\star c d}$ B. Dash ${ }^{\star a b}$ and \\ K. Sanjay ${ }^{\mathrm{ab}}$
}

Correction for 'An anionic and cationic surfactant-assisted hydrothermal synthesis of cobalt oxide nanoparticles as the active electrode material for supercapacitors' by R. R. Samal et al., New J. Chem., 2021, 45, 2795-2803; DOI: 10.1039/D0NJ05088A.

The authors regret that Scheme 1 was incorrect in the original manuscript. The corrected version of Scheme 1 can be found below. The Graphical Abstract image for the manuscript has also been updated to this corrected version of the image.

Furthermore, affiliation $a$ should read 'Academy of Scientific and Innovative Research (AcSIR), Ghaziabad-201002, India', as per the requirement of the authors' Academy. The correct affiliation $a$ is shown below.

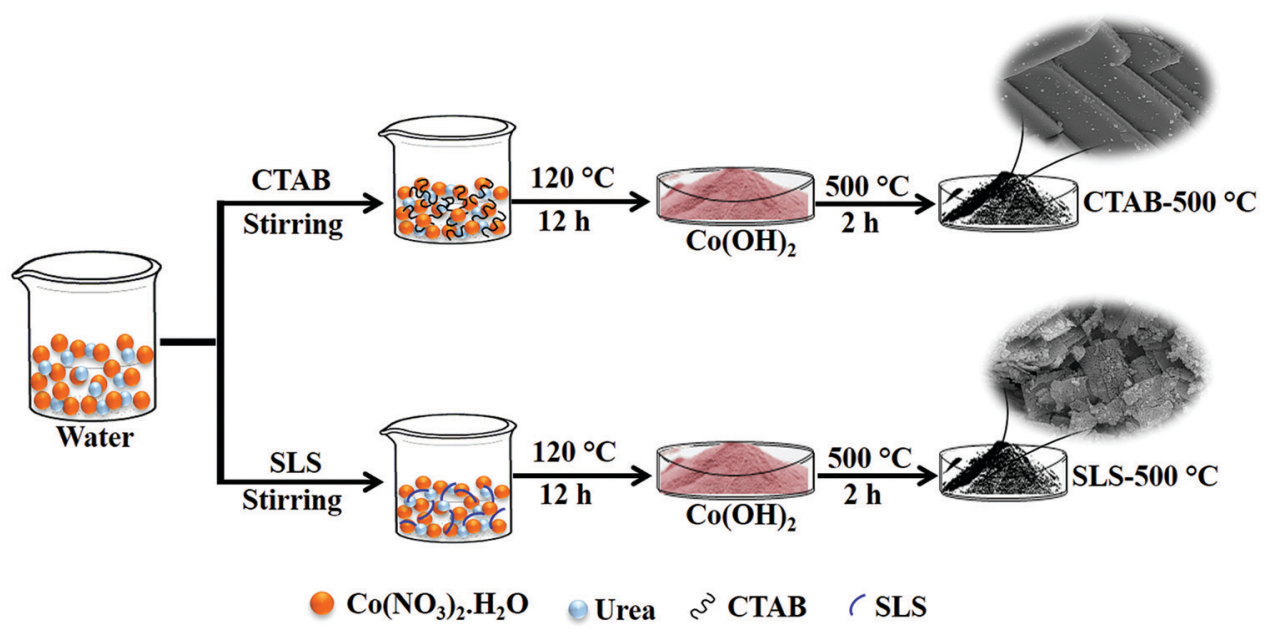

Scheme 1 Surfactant-assisted synthesis of cobalt oxide.

The Royal Society of Chemistry apologises for these errors and any consequent inconvenience to authors and readers.

\footnotetext{
${ }^{a}$ Academy of Scientific and Innovative Research (AcSIR), Ghaziabad-201002, India. E-mail: barsha.dash@gmail.com

${ }^{b}$ Hydro and Electrometallurgy Department, CSIR-Institute of Minerals and Materials Technology, Bhubaneswar - 751013, Odisha, India

${ }^{c}$ National Institute of Science Education and Research (NISER), Khordha 752050, Odisha, India

${ }^{d}$ Homi Bhabha National Institute (HBNI), Mumbai, India
} 